\title{
Excursões pela Amazônia
}

\section{Curt Nimuendajú}

Em setembro de 1922 iniciei, saindo do Pará, uma série de viagens para coletar material etnográfico e arqueológico para o Museu de Gotemburgo.

A primeira e rápida excursão teve por destino a Ilha de Marajó, conhecida pelos seus mounds e cemitérios de urnas: sua extremidade setentrional, o cabo Maguari, foi examinada com o objetivo de encontrar vestígios de antigas ocupações indígenas. Lamentavelmente, justo essa parte da ilha revelou-se uma formação bem recente de dunas: a linha costeira encontra-se em constante avanço em direção ao mar. Faltavam assim vestígios mais pronunciados da antiga população e a coleta restringiu-se a alguns cacos cerâmicos de pouca importância. Foi impossível estender a investigação à área geologicamente mais antiga vizinha ao rio de Soure, onde haviam sido constatados diversos cemitérios de urnas, em razão da atitude negativa dos latifundiários locais.

Um mês depois de voltar dessa excursão, o inspetor do SPI (Serviço de Proteção ao Índio) em Manaus pediu-me para organizar a administração dos postos entre os Parintin e Mura-Pirahá no rio Maici, um afluente esquerdo do rio Marmelos (região do Madeira). Entre os primeiros, com os quais apenas em maio do mesmo ano eu conseguira estabelecer os primeiros contatos pacíficos, organizei uma grande coleção, a primeira a ser levada a um museu europeu (Nimuendajú, 1924).

Em fevereiro de 1923, voltei ao Pará e resolvi empreender primeiro uma viagem ao alto Tapajós para estudar os Munduruku e Apiaká; mas uma estada de 14 dias em Santarém levou-me de início à descoberta dos estratos culturais extraordinariamente interessantes e ricos sobre os quais a atual cidade está edificada, e que se estendem pelas terras 
altas vizinhas, como foi imediatamente verificado. Adiando a investigação desses importantes achados, subi o Tapajós e, embora já tivesse superado as suas cachoeiras mais perigosas, tive de desistir da continuação em Pimental, devido ao péssimo estado do barco a motor em que eu viajava. Voltei a Vila Braga, próxima à cachoeira inferior do Tapajós, e resolvi dali ir visitar os índios Maué. Dirigi-me, portanto, ao povoado Tamanqueira, situado no interior, local que os Maué às vezes visitam para fins de comércio. De fato, logo depois de minha chegada, ali apareceram cinco índios e em sua companhia atravessei a pé o divisor de águas do Tapajós, entrando na região das cabeceiras do rio Mariacuã. Por falta de transporte, fui descendo pela margem desse rio até encontrar o chefe maué José Leão, que me recebeu com extraordinária desconfiança. Acabei descobrindo a razão disso: há seis anos os Maué haviam sido instigados contra "espiões alemães”! Proceder a um estudo etnológico em tais circunstâncias era impensável; retomei a viagem sob risco de vida. Além disso, os Maué já se encontram fortemente deculturados. Embarquei por fim com alguns índios no rio Mariacuã e, depois de passar por 11 assentamentos dos Maué, cheguei ao rio Mamuru, em cuja descida houve uma premente falta de víveres, até sua foz no lago Uaicurapá, desembocando finalmente com meus companheiros índios no Paraná do Ramos e no Amazonas, bem perto da cidade de Parintins.

Voltei a Santarém para continuar a investigar os vestígios encontrados na foz do Tapajós. Como nos antigos sítios do alto Tapajós (em Itaituba e atrás de Vila Braga), eu havia me deparado com os restos de uma outra cultura com enterro secundário em urnas e com cerâmica exclusivamente gravada, interessava-me verificar a extensão da cultura de Santarém. Para isso, empreendi primeiro uma excursão subindo pela margem direita do Tapajós até Samaúma, depois a cavalo novamente até as terras altas e por fim uma viagem de canoa até o Lago Grande de Vila Franca. Em todos os lugares encontrei apenas vestígios extremamente numerosos da cultura de Santarém, que talvez possa ser atribuída 
Revista de Antropologia, São Paulo, USP, 2001, v. 44 nº 1.

principalmente aos Tapajós, extintos como tribo autônoma já no final do século XVII. Ela se caracteriza pela total ausência de sepulturas - praticava-se a cremação e o consumo das cinzas em bebidas e, em parte, também uma espécie de mumificação - e por uma cerâmica completamente diferente, de espantosa riqueza de formas e alta elaboração artística que, de um lado, evidencia um parentesco inconfundível com a velha cultura Chiriqui do Panamá e, de outro, estranhas concordâncias, às vezes até nos mínimos pormenores, com a das Pequenas Antilhas.

Depois de uma permanência de três semanas no Pará, iniciei uma nova excursão visando a área costeira da Guiana brasileira. Primeiro encontrei ali, na região do rio Coanani, aquelas estranhas pedras fincadas com que ainda me deparei várias vezes durante esta viagem. As pedras, das quais algumas têm um comprimento entre três e quatro metros, são toscamente desbastadas num formato de pilar e foram trazidas das cachoeiras dos rios, às vezes a uma distância considerável, até os terrenos baixos do litoral. Ali se encontram, por vezes em grande número e sem ordem aparente, fincadas em lugares a salvo de enchentes, e hoje são freqüentemente derrubadas por caiadores de tesouros. As escavações revelaram alguns cacos de cerâmica, mas nenhuma evidência concludente de que as pedras indiquem sepulturas, tal como eu supunha a partir dos achados de Goeldi no Coanani.

Não muito longe da foz do rio Coanani, visitei o Monte Mayé, uma colina isolada de uns quarenta metros de altura, cercada por pântanos quase intransponíveis. No topo, parcialmente protegidos por rochas inclinadas, encontrei três sítios de urnas pré-colombianos que continham numeroso material complementar. Também no Mayacaré encontrei, nos pântanos da região costeira, um pequeno mound, cheio de urnas e pedras fincadas aparentemente pré-colombianas, evidenciando-se três estratos distintos. Por outro lado, encontrei os sítios de urnas superficiais, mais ao sul, próximos aos rios Amapá Grande, Serra e Flechal, todos destruídos e saqueados, sem exceção. 
Depois dessa permanência de dois meses na Guiana, fiz uma nova tentativa para entear em Marajó. De Chaves, na costa norte dessa ilha, fui primeiro para a ilha situada em frente, Mexiam, onde se dizia existirem diversos sítios com urnas, mas o proprietário explicou-me que uma visita não seria possível agora. Dirigi-me então à Fazenda Cajueiro no rio Arapixi na qual existe um grande mound com rica cerâmica mas não obtive autorização para a investigação, pois o dono estava ausente. Segui mais para o sul, em direção ao alto rio Cururu, onde encontrei um magnífico mound circundado de valas de água, cuja superfície parecia consistir quase inteiramente de pequenos cacos de cerâmica. Mas também aqui o dono não me permitiu escavar.

Desapontado, voltei para Chaves, mas decidi fazer ainda uma tentativa na ilha Caviana, antes de voltar ao Pará. A despeito de minha expectativa, tive boa acolhida, de modo que pude ainda examinar, pelo menos superficialmente, um cemitério de urnas no rio Apani. Parecia ser précolombiano: entre as urnas bastante toscas e que não continham material complementar, algumas apresentavam umas bocas estranhas, não viradas para cima, mas para o lado. Nos primeiras dias do ano de 1924 cheguei outra vez ao Pará.

Em maio desse ano fui novamente a Santarém para coletar mais material da cultura tapajó. Partindo de Alter do Chão, naveguei o rio Arapiuns até seus afluentes formadores onde já encontrei uma cerâmica bem diferente daquela dos Tapajós; por uma seqüência de canais laterais, cheguei ao Amazonas e examinei outra vez o Lago Grande de Vila Franca até os seus prolongamentos mais ocidentais, onde estabeleci a fronteira oeste da cerâmica tapajônica, também encontrando, além dos assentamentos permanentes na terra firme, montes de conchas e acampamentos temporários de pesca na várzea. Passando para a margem norte do Amazonas, examinei em seguida o delta do rio Nhamundá, cuja cerâmica constitui um tipo divergente, representando talvez os Konduri da época do Descobrimento. A volta fez-se pelo baixo Trombetas e pelo Amazonas até Santarém, de onde, após nova visita à 
Revista de Antropologia, São Paulo, USP, 2001, v. 44 nº 1.

terra firme, dirigi-me rio abaixo para o povoado de Monte Alegre na margem esquerda. Aqui a minha atenção voltou-se principalmente para as cavernas das montanhas areníticas de Paituna e Ereré, onde, entretanto, não constatei sinais de uso permanente. Mas nas duas montanhas encontraram-se pinturas rupestres executadas em vermelho e amarelo. Logo abaixo de Monte Alegre, um antigo assentamento em Pariçó forneceu algum material, ainda aparentado com a cultura tapajó, embora divergente em vários sentidos. Por falta de transporte, não foi possível estender a investigação à margem oposta do Amazonas.

De julho a outubro do mesmo ano fiz uma segunda viagem a Caviana. No rio Pacajá examinou-se um cemitério de urnas pós-colombiana com cerâmica simples e numeroso material complementar, como algumas contas de pedra verde. Outro cemitério de urnas em Bacabal parecia proceder da época da Descoberta e sua cerâmica novamente se diferenciava da anterior. Um quarto tipo surgiu no cemitério de urnas de Rebordelo, no qual as peias - em parte antropomorfas - apresentavam não apenas uma rica pintura, mas também ornamentos plásticos Os esqueletos, dois em algumas urnas, estavam pintados de vermelho. Entre os objetos complementares encontrei uma vasilha com miçangas européias. Infelizmente não pude examinar um outro cemitério de urnas em Prainha que parece conter uma cerâmica pintada muito bonita.

A ilha de Caviana em que os quatro cemitérios de urnas evidenciam igual número de tipos cerâmicos mostra claramente a complexidade da história do povoamento da foz do Amazonas: os dois cemitérios da época do Descobrimento, Apani e Bacabal, são totalmente diferentes. Nessa região só se tem notícia dos Aruã históricos, aos quais provavelmente pertenceram as urnas de Pacajá e talvez também as de Rebordelo; estas representando a cerâmica no momento do contato e as primeiras representando um período mais recente de decadência da arte oleira, com forte influência européia.

Depois dessas escavações em Caviana, dirigi-me para a Ilha dos Porcos, rio acima, onde eu ouvira falar de mounds cercados de restos 
de velhas paliçadas. Mas aconteceu o que já se dera tantas vezes: o proprietário das terras estava ausente e o administrador declarou não ter procuração. Também fracassou a tentativa de examinar as terras altas que beiram os estreitos de Breves.

Por volta do fim do mesmo ano empreendi ainda uma terceira viagem. Com um barco a vela fui de Alter do Chão no Tapajós para Óbidos, onde comprei de um velho aficcionado brasileiro quatro daqueles raríssimos ídolos de pedra que aparentemente apenas são encontrados na região de Santarém e Óbidos, e que, por associarem uma figura humana com a de um animal, representam uma das provas mais evidentes da influência meso-americana na Amazônia. Regressei novamente pelo Lago Grande de Vila Franca. Por canais laterais e pântanos da margem direita do Amazonas e passando por Santarém, visitei o baixo rio Curuá e o lago de Cuçari, mas ali tive de interromper os trabalhos porque fiquei doente. Os vestígios nessa região constituem uma continuação da cultura tapajó.

Em abril de 1925 eu estava restabelecido e pude empreender nova viagem à Guiana, na região do rio Oiapoque. De maio a agosto vivi ali, no rio Arucauá, com os índios Palikur, uma tribo aruak pacífica que, apesar de ser em parte miscigenada e creolizada, ainda conservava em essência a sua velha cultura: foi possível organizar uma coleção considerável que também incluía numerosos testemunhos de sua cultura espiritual, e muitos artefatos, os últimos do seu gênero provavelmente, pois a deculturação da tribo caminha a passos rápidos. Também fiz visitas mais demoradas aos índios do Uaçá e aos brasileiros indianizados do rio Curipi. Entre os achados no solo, destacaram-se as antigas e belas urnas funerárias dos Palikur e os destroços de urnas funerárias encontradas numa caverna natural da serra de Ucupi, idênticas àquelas localizadas por Goeldi nos poços funerários do rio Coanani. As investigações arqueológicas no baixo Oiapoque (Taparabo), entretanto, foram infrutíferas (Nimuendajú, 1926).

Uma malária muito forte me prendeu no Pará até janeiro do ano seguinte, mas depois encetei uma nova viagem com os objetivos 
Revista de Antropologia, São Paulo, USP, 2001, v. 44 nº 1.

principais de estudar os índios Mura e o cemitério de urnas de Miracanguera, um pouco acima de Itacoatiara na margem norte do Amazonas, descoberto por Barboza Rodrigues nos anos 80 do século passado. Ambos fracassaram: os Mura nos 16 assentamentos visitados perderam quase por completo as suas características e o terreno com a necrópole de Miracanguera fôra inteiramente arrancado pela correnteza do Amazonas. Toda a longa viagem de quase cinco meses foi feita numa pequena canoa com dois homens. Partindo de Alter do Chão no Tapajós, ela passou pelos lagos e afluentes da margem sul do Amazonas rio acima. Os antigos sítios do lago Curumucuri ainda revelavam a nítida influência da cerâmica de Tapajós, enquanto os da Serra de Parintins evidenciavam em contrapartida o estilo Konduri, conhecido da margem setentrional. Ao entrar no Paraná do Ramos, saí finalmente da área de ocorrência da cremação, penetrando na área dos sepultamentos em urnas. Por esse curso d'água que é um braço do Amazonas, cheguei ao Paraná de Urariá, um braço da foz do rio Madeira que subi até a sua bifurcação no rio principal. Aqui encontrei os primeiros restos de bandos Mura completamente deculturados. De Maués para cima, nos afluentes meridionais do Urariá (Apocuitáua, Paracuni, Abacaxi e Canumã), vivem índios Munduruku em condições não muito melhores; visitei-os no rio Paracuni. Os que habitavam o Canumã acabavam de ter um sangrento embate com castanheiros. Continuei a viagem pelo rio Madeira acima até a altura do rio Mataurá, visitei os bandos Mura que habitam os lagos e afluentes de ambas as suas margens, sempre obtendo maus resultados. A despeito da minha boa expectativa, o resultado das investigações nos antigos assentamentos da tribo Iruri no rio Mataurá foi pobre. Já conhecendo numa ocasião anterior os bandos Mura que habitam mais acima no Madeira, regressei daqui e por um afluente entrei na região dos lagos do Autaz que preenche o ângulo entre o baixo-Madeira e o Amazonas, no caso o Solimões. Durante cinco semanas revistei-a até os mais afastados confins procurando representantes razoavelmente primitivos da tribo 
dos Mura. Nesse momento, a minha última esperança era o bando Yuma, mas encontrei sua aldeia abandonada; topei depois com o mísero resto de um bando, outrora numeroso, numa fazenda onde, arruinados pela doença e pelo vício de fumar liamba, "trabalhavam" para o seu proprietário. Pelo rio Autaz alcancei de novo o Amazonas; mas dos Mura, no lugar de uma coleção etnográfica, eu trouxe um maço de queixas sobre invasões de terras e outros maus tratos por parte dos civilizados, as quais eu submeti conscienciosamente ao inspetor do SPI em Manaus.

Transferi agora o campo de trabalho para o lado norte do Amazonas e depois de ter verificado que em Miracanguera nada mais se podia fazer, entrei no rio Urubu através do canal Arauató, acima de Itacoatiara, subindo um trecho e depois descendo por ele até a foz no lago Saracá. Depois de ainda visitar rapidamente o curso baixo do rio Uatumã, que se parece com um lago, atingi outra vez o Amazonas através do Paraná de Urucará. Dos Mura do rio Urubu, apenas encontrara alguns indivíduos, e nenhum representante dos Arauaki de Sant'ana no Uatumã, o que muito lamentei, pois o único vocabulário dessa tribo outrora muito importante, recolhido por Barboza Rodrigues, pelo visto se extraviou. Em compensação, ouvi falar de um conflito de seringueiros com uma tribo desconhecida no alto Autumã; as flechas recolhidas, de tão parecidas, podiam ser confundidas com as dos aguerridos Yauaperi do afluente homônimo da margem esquerda do baixo rio Negro.

Os velhos assentamentos, em especial do rio Urubu e do lago Saracá, forneceram numeroso material cerâmico que representa um novo tipo; curiosamente, ele ocorre também numa forma afim em Santarém, no centro da área da cultura Tapajó, num pequeno sítio situado na extremidade ocidental da cidade (Leiteria do Montenegro). Um outro tipo cerâmico encontra-se abaixo da foz do Paraná de Urucará, nas colinas de Paurá, na margem setentrional do Amazonas. Cemitérios de urnas não foram constatados em toda essa área. O regresso se fez via Parintins, de novo pelo lago Curumucuri e Santarém. 
Revista de Antropologia, São Paulo, USP, 2001, v. 44 nº 1.

Na realidade, o campo de trabalho seguinte deveria ser a região do rio Negro, pois o Professor Erland Nordenskiöld me havia pedido material da bacia desse rio para a sua viagem ao Orinoco, planejada para o próximo ano. Por diversas razões, porém, decidi ainda aproveitar o resto do ano para uma visita aos índios Apinayé no extremo norte de Goiás; alguns deles haviam estado no Pará e convidaram-me a participar de suas festas religiosas quando de seu regresso. A falta de recursos e de tempo, bem como a desconfiança dos comerciantes sírios que monopolizam os transportes levaram ao fracasso dessa excursão pelas corredeiras do Tocantins. Alguns sítios de antiga ocupação indígena na margem direita desse rio forneceram um material que mereceria maior atenção.

Em 3 de fevereiro de 1927 iniciei a viagem ao rio Negro, para a qual também recebi uma subvenção do inspetor do SPI, pois as crescentes queixas dos índios locais sobre maus tratos por parte de seringueiros brasileiros e principalmente colombianos exigiam já há muito tempo um exame das condições e a escolha de um lugar para a instalação de um posto. A viagem foi, em parte, uma repetição da expedição de Koch-Grünberg de 1903. De vapor, de barco a motor e finalmente a remo subi o rio Negro até São Felipe. Dali continuei a viagem em dois pequenos barcos com a tripulação indígena, navegando o rio Içana acima até Yandu-Cachoeira. Voltando por ele, entrei no rio Ayari, subindo até as últimas moradas dos índios. Novamente voltei um trecho nesse rio, fui por terra até Yutica no rio Uaupés, subi por ele até o seu afluente Querari, descendo por este até sua foz no rio Negro. A população da bacia do Içana (com exceção do alto Ayari), bem como parte do alto Guainía, é formada por uma única tribo que não tem autodenominação em sua própria língua e é chamada "Baúa" pelos civilizados, o mesmo nome de uma outra tribo aruak na Venezuela. Essa tribo - tal como os Palikur e outras da mesma família - divide-se em pelo menos 16 clãs localizados, exogâmicos, que falam todos a mesma língua em três ou quatro dialetos pouco diferenciados. Os três ou quatro 
primeiros clãs no baixo Içana, que possuem um dialeto, apresentam o apelido coletivo de "Kárutana"; os clãs que habitam a parte mais alta do mesmo rio e no alto Guainía, com dialetos um pouco mais divergentes, são chamados de "Coripáco" pelos venezuelanos. O curso superior do Ayari, desabitado na época de Koch-Grünberg, é hoje ocupado pelo clã Dyurémawa dos Kobéwa, procedente do vizinho Querari. Entre os Wanána do rio Uaupés presenciei uma festa de máscaras associada ao culto dos mortos; ao contrário da informação de Koch-Grünberg de que os Wanána não possuíam máscaras de dana, esta é hoje a única tribo da região (com exceção de alguns clãs Kobéwa em território colombiano) a ainda confeccionar algumas; no Ayari elas não são encontradas atualmente.

Ao descer o rio, verifiquei que a língua Tariana já foi inteiramente suplantada pela Tukana: nem em Yauareté e nem em Ipanoré me foi possível encontrar uma pessoa que me pudesse fornecer um vocabulário. A $15 \mathrm{~km}$ ao sul-sudoeste de Yauareté, no interior, visitei uma horda de Makus; com exceção de sua língua, eles infelizmente estavam completamente tarianizados. Em Yauareté acabaram-se as minhas mercadorias de troca, de modo que fui obrigado a desistir de uma visita aos rios Papuri e Tiquié que prometiam resultados melhores, e voltar rapidamente para o rio Negro. Também na área do Içana e na do Uaupés o número de índios diminui com inquietante rapidez: na primeira bacia ele decresceu para cerca de um terço desde a visita de Koch-Grünberg, naquela época os Kadaupurítana (Katapolítani) contavam com 200 cabeças, hoje não chegam a 20. A cultura dos índios é espezinhada pelas forças unidas de seringueiros e missionários; pelos primeiros porque ela aproxima os índios do "trabalho", isto é, da prestação de serviços escravos para os seringueiros; pelos segundos, porque ela não cabe no padrão da assim chamada civilização "cristã". Os receios que Koch-Grünberg expressa ao fim de seu livro sobre a viagem ao rio Negro realizaram-se por inteiro.

Durante esta viagem examinei em dois locais cemitérios de urnas com enterro secundário em cavernas naturais. O primeiro sítio com urnas 
encontrava-se na encosta da colina Carmo-Iuitéra, pouco acima de Sant'Ana na margem esquerda do Içana. Evidenciou-se apenas uma única urna com a parte superior já destroçada; os "Karútana" de Sant'Ana informaram que ela pertencera aos seus próprios antepassados. O segundo sítio de urnas estava ao pé da colina Anuyá-Iuitéra próxima à aldeia Jacaré-rapecuma, na margem esquerda do baixo rio Uaupés. As urnas, das quais algumas eram particularmente bem pintadas, muito lembravam as velhas urnas dos Palikur. Estavam enterradas a pouca profundidade. Não pertenciam às tribos Tukana que hoje aqui habitam, mas provavelmente aos seus predecessores Aruak. Consta que também na ilha Cuya-Capuáma, formada pelos dois braços da foz do Uaupés, existem diversos sítios com urnas sobre uma colina rochosa (Yacundá-Iuitera), mas não consegui encontrá-los.

Com esta viagem encerrou-se o meu trabalho para o Museu de Gotemburgo.

Pará, 28 de novembro de 1927.

Curt Nimuendajú.

Tradução de Thekla Hartmann. 
Curt Nimuendajú. Excursões pela Amazônia

\section{Notas}

1 Original em alemão "Streifzuege in Amazonien", publicado em Ethnolo- Anzeiger (vol. II , Stuttgart, 1929-1932, p. 90-7).

\section{Bibliografia}

NIMUENDAJÚ, C.

1924 "Os índios Parintintin do rio Madeira", Journal de la Société des Américanistes de Paris, vol. XVI.

1926

Die Palikur-Indianer und ibre Nachbarn, Göteborgs Kungl, Vetenskaps-och Vitterhets-Samhälles Handlingar, Fjärde-Följden, vol. 31(2). 